\title{
Calvyn oor die koninkryk van God
}

\author{
en die staat
}

\author{
A le R du Plooy \\ Potchefstroomse Universiteit vir CHO
}

\begin{abstract}
Calvin on the kingdom of God and the state

This article focuses on the relationship between the kingdom of God and the state. An attempt is made to put into perspective Calvin's distinction between the spiritual dominion (regnum spirituale) and the political dominion (regnum politicum). According to Calvin these two kingdoms should be distinguished and understood in the light of the kingdom of God. It is argued that the political dominion should seek to serve the kingdom of God in its own sphere. Secular governments should therefore establish and preserve civil justice and order so that God can be glorified.
\end{abstract}

\section{INLEIDING}

In hierdie artikel konsentreer ek hoofsaaklik op enkele aspekte van die relasie tussen die koninkryk van God en die staat (veral die staatsowerheid) soos dit uit die standpunte van Calvyn blyk. Dit is ' $n$ onderwerp wat waarskynlik te min aksent ontvang en moontlik onderbelig is, maar dit is tog verhelderend ten opsigte van die begronding en bedoeling van Calvyn se twee-rykeleer.

Ek wil probeer aantoon dat Calvyn se regimen spirituale nie volkome met die koninkryk van Christus saamval nie en dat die regimen politicum of politieke ryk net soos die geestelike ryk in diens van die koninkryk van God is.

Aangesien professor A D Pont homself as ' $n$ kenner en liefhebber van Calvyn onderskei het en ook 'n besondere bydrae op die terrein van die hervormde of refor- 
matoriese ekklesiologie gelewer het, wil ek die hoop uitspreek dat die bydrae hom sal interesseer.

Die huidige situasie in Suid-Afrika vereis dat prinsipieel besin sal word oor die basiese grondslae van 'n staat en staatsowerheid. Op watter fondamente gaan die 'nuwe Suid-Afrika' rus? Wat gaan die reformatoriese Christene se antwoord wees op die sekulêre en sosialistiese aanslag? Dit is van aktuele belang dat opnuut kennis geneem word van Calvyn se vertrekpunte wanneer hy oor die burgerlike regering handel, omdat hy ons by die Skrif bring wat hy ook verhelderend uitlè en toepas.

Uiteraard kan en hoef 'n mens nie volledig op Calvyn se weergawe van die grondslag, taak en doel van 'n staatsowerheid in te gaan nie, omdat dit in die gereformeerde teologie redelik bekend is en dikwels daaroor geskryf is (vgl Du Plessis 1932; Du Plessis 1974). Ek beperk my hoofsaaklik tot Calvyn se uitgangspunte en is veral geïnteresseer in die vertrekpunte wat agter sy standpunte oor 'n burgerlike regering lê. Agtereenvolgens word die aandag op die volgende aspekte gevestig:

- 'n Oorsigtelike aanduiding van die agtergrond waarteen en motivering waarom

Calvyn oor die koninkryk van God en die staat geskrywe het.

* Die koninkryk van God en die twee-rykeleer van Calvyn.

- Die koninkryk van God en die burgerlike regering.

* 'n Christelike staat.

- Gevolgtrekkings.

\section{AGTERGROND}

Wanneer Calvyn (1509-1564) op die toneel verskyn, is die eenheidsorganisasie van die Romeinse Ryk feitlik op sy einde en is die corpus christianum opvatting van die Middeleeue deur die toedoen van Luther vernietig.

Die twee-swaardeleer van die Rooms-Katolieke Kerk moes plek maak vir Luther se twee-rykeleer waarvolgens die godvresende vors (die praecipium membrum ecclesiae) die én swaard in sy nasionale staat moes dra. Die godvresdende vors is die enigste persoon wat in die kerk en land regeer en word van die kerk se kant van advies bedien (Pont 1985:430).

Dit is 'n tyd waarin nasionale state en territoriale monargieë ontstaan en waarin veral twee vorme van soewereine state na vore kom, naamlik 'n federalisties-republikeinse kleinstaat (soos Genève) en 'n monargaal-al solutistiese grootstaat (soos Frankryk). Calvyn het in Frankryk en in Genève hiermee kennis gemaak (Du Plessis 1932:77; Baur 1965:97-100).

Calvyn sou egter ook te doen kry met die standpunte van Erastus en sy volgelinge (ofte wel met Caesoropapisme), waarvolgens die owerheid alle seggenskap oor 
die uiterlike kerk as 'n Christelike gemeenskap het. Slegs die Woord- en sakramentsbediening staan buite die bevoegdheid van die owerheid (Pont 1985:435-439). In die Erastianisme het ons ' $n$ vorm van staatsabsolutisme.

Aan die ander kant het Calvyn intense probleme met die Dopers gehad. In hulle geledere was daar groepe wat die staat weer totaal verag het (vgl Balke 1973:268: 273).

In Calvyn se eerste Institusie (1536) rig hy inleidend 'n brief aan koning Frans I van Frankryk. Hierin word Calvyn se standpunte oor 'n owerheid goed gereflekteer. Dit word ook duidelik dat hy en sy volgelinge nie met die Dopers verwar moet word nie, dat 'n koning 'n dienaar van God is en nie 'n tiran mag wees nie. So spreek hy hom teen die vervolgsugtigheid van Frans I uit asook teen die anargie van die Dopers. In 1535 het die ekstreme standpunte van die Dopers juis tot 'n bloedbad in Münster gelei (vgl Steenkamp 1986:353-354; Landwehr 1924:66-67).

In die lig hiervan is dit nie vreemd dat Calvyn reeds in 1536 (Inst hfst 6) oor die owerheid handel nie en in 1559 (Inst 4, 20) volledig daaroor skryf nie. Hy handel ook daaroor in sy ander geskrifte, maar nêrens so volledig soos in sy Institusie van $1559(4,20)$ nie (vgl Du Plessis 1932:51).

Die Dopers het dit gepropageer dat 'n Christen geen burger van ' $n$ staat is nie en niks met 'n burgerlike owerheid te doene het nie. Omdat dit vir Calvyn 'n gevaarlike kettery was, veral in die lig van die bedreiging van Frans I teenoor die Franse protestante, was die Anabaptisme sy eerste vyand in sy leer oor die owerheid (Balke 1973:59).

Behalwe die genoemde historiese agtergrond kan ons aansluitend hierby ' $n$ teologiese motivering vir Calvyn se behandeling van die burgerlike regering (en kerkregering) bemerk. Du Plessis (1932:50-51) toon aan dat Calvyn se behandeling van die staat nie soseer vanuit sy belangstelling in die staat as sodanig gemotiveer is nie, 'maar alleen in so ver dit betekenis het vir die kerk en die saligheid, of liewer vir die eer van God'.

Calvyn was meer geinteresseerd in die koninkryk van God en het ook ' $n$ besonder noue relasie tussen die koninkryk en die kerk gesien (Calvyn 1980:484; Du Plooy 1982:330). Wanneer hy dan in 1536 - teen die agtergrond van veral die Doperse standpunte - teologies oor die vryheid van 'n Christen skryf (Inst 3, 19), gee hy perspektief op die betekenis en bedoeling van die vryheid van 'n Christen en dui hy veral ook aan wat vryheid nie beteken nie. Hy verwyt die Dopers dat hulle nie goed genoeg onderskei tussen die koninkryk van Christus en die burgerlike owerheid nie: 'Zodra zij horen dat in het Evangelie een vrijheid beloofd wordt die geen koning en meester onder de mensen erkent, maar alleen op Christus ziet, 
menen zij dat zij zich niet in hun vrijheid kunnen verheugen, zolang zij nog een ambtelijk gezag boven zich zien' (Balke 1973:61).

Wanneer Calvyn dus oor die Christelike vryheid skrywe, stel hy dit teenoor die Dopers dat hierdie vryheid wat die koninkryk van God meegebring het met die koms van Christus, nie beteken dat 'n Christen losgemaak is van gehoorsaamheid en onderwerping aan 'n burgerlike en kerklike regering nie. Die burgerlike regering is juis deur God gegee as 'n uitwendige genademiddel (extermum medium salutis - Inst 3,$19 ; 4,20,1$; Balke 1973:71). Beide regerings (die geestelike en die burgerlike) is op aarde werksaam om die koninkryk van God te bevestig en te bevorder (Inst 4, 20, 1-2; Schoch 1902:83).

Die historiese en teologiese agtergrond waaraan hierbo aandag gegee is, verklaar in 'n groot mate waarom Calvyn met sy Skriftuurlike visie op die koninkryk van God korrigerend teen die strominge en teorieë van sy tyd gereageer het. Samevattend kan opgemerk word dat vanweë 'n prinsipiële misvatting ten opsigte van die koninkryk by Rome, daar by Luther en die Anabaptiste ook 'n wanopvatting met betrekking tot die staat bestaan: By die Rooms-Katolieke Kerk se twee-swaardeleer - waarvolgens alle mag in kerk en wêreld in die pous saamtrek en hy as die verteenwoordiger van Christus op aarde beskou word - lê die fout reeds by die totale identifisering van koninkryk en kerk. Die Rooms-Katolieke Kerk is as een sigbare heilsinstituut heeltemal met die koninkryk van God vereenselwig. Dit is beskou as die beliggaming van die hemelse ryk op aarde (Plöchl 1960:126; Berkhof 1969:232). Gevolglik was die vorste aan die gesag van die kerk soos dit in die pous saamtrek, ondergeskik.

Calvyn het ook 'n korreksie in Luther se twee-rykeleer aangebring. Volgens Luther val die onsigbare kerk as die geestelike ryk van Christus volkome saam met die koninkryk van God (Lindijer 1962:104). Hierdie onsigbare kerk is eksklusief die koninkryk. Die wêreldlike ryk waar God deur die owerheid of vors oor alle uiterlike en uitwendige, insluitende kerklike sake, regeer, staan dus te los van die konkinkryk van God. Balke (1973:71) wys daarop dat Luther nie daarmee moes volstaan het deur net te sorg dat die Woord verkondig word nie. Calvyn het verder gegaan en na weë gesoek om die Woord van God en die koninkryk (Gods heerskappy) ook gestalte te laat kry in die konkrete samelewing en in die owerheid as die externum medium salutis.

Die Dopers het weer - soos die Novatianiste en Donatiste van ouds (vgl Balke 1973:117-118) - geglo dat die kerk in wêreldvermyding moet opgaan en dat die koms van Christus die Christen in die staat van volmaaktheid geplaas het. Die owerheid is slegs daar om die orde in die wêreld wat nog in die bose lêt te handhaaf. Die politiek val volgens hulle buite die bestek van die Nuwe Testament. Die evan- 
gelie bevat beginsels om die lede van die koninkryk van die hemel te regeer, maar nie vir die wetgewing van 'n sekulêre staat in die wêreld wat nog in die bose lê nie. Daarom mag 'n Christen ook geen rol in die staat vervul nie (Balke 1973:268).

\section{DIE KONINKRYK VAN GOD EN DIE TWEE-RYKELEER VAN CAL- VYN}

Calvyn neem sy vertrekpunt by God wat deur sy Woord en Gees 'n nuwe geheiligde gemeenskap, naamlik die kerk op aarde skep. So is die kerk die begin van die deurbraak van die koninkryk van God op aarde (Bohatec 1961:272; Lindijer 1962:105; Schoch 1902:38). Hierdie gemeenskap kom alleen tot stand deur die proklamasie van die koningskap van Jesus Christus.

Die koninkryk van God moet nie soos by die Rooms-Katolieke Kerk met die sigbare kerk op aarde geïdentifiseer word nie, want dit moet nog in sy voleinding kom. Die koninkryk kan ook nie totaal vergeestelik word nie, want dit het reële gevolge op aarde en daagliks groei en bloei dit (Balke 1973:276). Aan die ander kant beteken dit nie dat die koninkryk reeds ten volle op aarde gerealiseer het en met 'n aardse koninkryk vereenselwig kan word nie.

In Calvyn (1965:252) se kommentaar op Filippense 2:10 stel hy dat die koninkryk daagliks groei en ten goede vorder, maar dat dit nog nie volmaak is nie. Dit is waar dat almal hulle aan God se heerskappy moet onderwerp, maar ook dit sal voor die wederkoms nie ten volle gebeur nie. Wat nou slegs begin het, sal dan voltooi wees. Hier het Calvyn waarskynlik die Dopers in gedagte.

Calvyn leer dat 'God in sy genade die innerlike, geestelike regering en ook die uiterlike burgerlike regering aan die mensdom gegee het wat, hoewel duidelik van mekaar onderskeie, albei gerig is op die koninkryk van Jesus Christus (Inst 3, 19, 14 15; Balke 1973:277-278). Die duidelike onderskeid wat Calvyn tussen die geestelike en burgerlike regering maak, beteken nie dat hy daarmee bepaalde aspekte van die lewe van die heerskappy van God wil wegneem nie. Daar is geen aardse ryk wat met die hemelse ryk saamval nie (Inst 3, 19, 15; 4, 20, 1).

Die belangrike verskil tussen Luther en Calvyn lê daarin dat waar Luther die kerk as die geestelike element in 'n Christelike staat beskou, Calvyn dit so stel dat die kerk nie bloot as die geestelike sy van die staat beskou moet word nie. Die kerk is tegelyk onsigbaar en sigbaar en volgens Calvyn ook georganiseer onder die Hoofskap van Christus met sy eie regering en dissipline. Die kerk is die gebied waar Christus in besonder regeer en as koning heers. Die kerk is reeds die realisering van die koninkryk op aarde, hoewel nog onvolkome (Inst 4, 1, 20; vgl ook kommentaar van Calvyn 1845:118-120, 133 op Matt 13:24, 47; Schoch 1902:38, 83, 116-117). 
Van 'n heerskappy van die staat oor die kerk mag geen sprake wees nie, juis omdat beide (kerk en staat) aan die koninkryk van God ondeworpe is en elk sy eie afsonderlike taak en roeping in diens van God het! Die dienaars in die kerk en staat moet begryp dat hulle in diens van God en sy koninkryk is. Daarom beklemtoon Calvyn dat die gelowiges nie moet opgaan in wêreldmyding nie, maar hulle roeping moet sien in die heiliging van die wêreld (vgl Balke 1973:286). Hierin moet die geestelike en burgerlike regering diensbaar wees, want hierdie twee ryke is vir Calvyn soos twee oë van een mens of soos twee arms van een liggaam (vgl kommentaar van Calvyn 1864-1897:659-660 op 1 Sam 11:6-10). Hy beskou die kerk as die siel van die menslike samelewing en die staat as die liggaam waarbinne die siel werksaam is. Albei het uiteindelik dieselfde gerigtheid naamlik om die koninkryk van God op innerlike en uiterlike wyse te dien en te bevorder (Inst 4, 20, 1-2; Schoch 1902:117).

\section{DIE KONINKRYK VAN GOD EN DIE BURGERLIKE REGERING}

Hoewel die geestelike ryk deur die verkondiging van die evangelie die beginsels van die koninkryk van die hemel in ons bewerk, is dit ook waar dat ons nog in onvolmaaktheid lewe. Daarom het God ook die burgerlike regering gegee as sy dienaar en as hulpmiddel om die uiterlike godsdiens te onderhou en te beskerm en om die gesonde leer en die kerk ter wille te wees (Inst 4, 20,2). Die burgerlike regering is noodsaaklik om te voorkom dat die orde van God omver gewerp word en om sorg te dra dat die openbare godsdiens vir die Christene gestalte sal verkry (Inst 4, 20,3).

Calvyn behandel dan agtereenvolgens die burgerlike regering in sy onderdele, naamlik

- die owerheid as die bewaker van die wette (of die reg - Du Plessis 1974:102);

- die wette (of reg) waarvolgens die owerheid regeer;

- die volk of onderdane wat aan die wette (die reg) onderworpe is.

Calvyn behandel hierdie drie fasette van die regnum politicum in sy Institusie $(4,20$, 4-32). Vir 'n bespreking daarvan kan onder vele meer verwys word na Lubbe (1964:200-208), Du Plessis (1974:102-106; 1986:178-183) en Steenkamp (1986:353374). Ons aksentueer slegs enkele aspekte in sover dit met die bedoeling van hierdie artikel te doen het.

\subsection{Die owerheid}

In hierdie gedeelte wat oor fundamentele aspekte van die owerheid handel, beklemtoon Calvyn dat die koms van die koninkryk op aarde nie die owerhede oorbodig 
gemaak het nie (Inst 4, 20, 4-6; Balke 1973:268-273). Die pligte en funksies van die owerheid strek uit oor beide tafels van die Dekaloog en die owerheid moet as uiterlike regering toesien dat die hele samelewing in geregtigheid, vryheid en sedelikheid ordelik bestaan. Die beginsels van die koninkryk van God moet gevestig en beskerm word (Inst 4, 20, 9-13).

Balke (1973:273) konkludeer soos volg: 'Het overheidsambt is een goddelijk ambt. In het handhaven van orde en recht is de owerheid dienstbaar aan de komst van het Koninkrijk. Het wereldlijk ambt wordt door Calvijn zedelijk en religieus gekwalifiseerd, het is een "vocatio" een roeping van God.'

\subsection{Die wette (of reg)}

Calvyn het 'n diepe afkeer in anargie en wetteloosheid gehad. Dit hang saam met sy beskouing oor God. God is vir hom nie 'n wettelose God nie, maar 'n God van orde en reg (Milner 1970:7-70). Om sy koninkryk op aarde te laat realiseer maak God instrumenteel van mense as sy dienaars gebruik. Hy regeer nie onmiddellik nie, maar middellik, deur middel van sy Woord, deur middel van wette en deur middel van mense wat hy in ampte roep (Balke 1973:290).

Juis daarom plaas Calvyn 'n geweldige hoë premie op die wette van 'n owerheid en noem hy dit die sterkste senuwees van 'n staat waarsonder 'n owerheid nie kan regeer nie. Die aard van die wette moet so wees dat dit godvrugtig is en behoorlik tot diens van die mense gebruik moet word (Inst 4, 20, 14).

\subsection{Onderdane}

In die gedeelte waar Calvyn oor die gehoorsaamheid van die onderdane aan hulle owerheid handel (Inst 4, 20, 17-32), word dit duidelik dat sy koninkryksperspektief ook hier 'n besondere rol vervul. Die gehoorsaamheid aan die owerheid word naamlik bepaal deur die feit dat die owerheid steeds dienaar van God en sy koninkryk is. God dra nie sy mag en sy heerskappy aan die konings en vorsto oor wanneer Hy hulle aanstel nie. God bly Koning, terwyl vorste en owerhede die dienaars is (Inst 4, 20, 32).

Ongehoorsaamheid aan die owerheid is verset teen God self. Selfs owerhede wat van God afdwaal en Godonterend optree, moet gehoorsaam word. Slegte owerhede is ook ' $n$ teken van die straf en tug van die Here. 'n Goeie regering is 'n gawe van God. Omdat God egter koning is, mag daar ook nie aan 'n aardse vors meer onderdanigheid betoon word as aan God nie (Inst 4, 20, $25-27$ en 32). 
Hierdie standpunte van Calvyn mag vreemd klink, maar kan maklik verstaan word wanneer dit vanuit sy koninkryksperspektief beskou word. God as koning regeer oor sy koninkryk wat nie van hierdie wêreld is nie en tog beteken dit nie dat God Hom daarmee van die bestaande politieke orde in die wêreld onttrek het nie. Die onderdane van die koninkryk van God kan daarmee getroos wees dat daar meer is as 'n blote aardse koninkryk van konings en vorste; die koninkryk van God woon in die harte van sy kinders (Calvyn 1961:166).

In sy kommentaar op Johannes 18:36 (Calvyn 1961:166) vra Calvyn die vraag of die koninkryk van Christus met wapengeweld verdedig mag word. Hy antwoord dat dit verkeerd is om uit hierdie teks af te lei dat die leer van die evangelie en die suiwere godsdiens nie met wapengeweld verdedig mag word nie. Tog wys hy die praktyk van Karel die Grote af om die koninkryk van Christus met die swaard te bevorder (vgl Balke 1973:299). Die koninkryk van Christus wat wesenlik geestelik is, moet immers in die leer en in die krag van die Gees gefundeer word. Wette en dekrete van mense dring nie in gewetes in nie. Tog neem dit die feit nie weg dat vorste by geleentheid die ryk van Christus mag beskerm nie - deels deurdat hulle die uiterlike tug vasstel en deels deurdat hulle aan die kerk beskerming teen die goddeloses verleen. Dan voeg hy in hierdie kommentaar die volgende merkwaardige opmerking daaraan toe: Die boosheid van die wèreld veroorsaak dat die koninkryk van Christus meer deur die bloed van martelare bevestig word as deur die hulp van wapens.

Calvyn beklemtoon dit egter dat reg en orde die koninkryk bevorder en dat God deur sy Woord en Gees regeer. God wil die wèreld nie deur geweld nie, maar deur die roepstem van die prediking van die evangelie en die krag van die Gees aan Hom onderwerp. Die geestelike ryk mag mense nie met geweld tot geloof dwing nie en tog kan die burgerlike regering die kerk as die siel van die liggaam (die staat) met die swaard verdedig - omdat die vermoording van die siel erger is as die vermoording van die liggaam (vgl Balke 1973:303).

\section{5. 'N CHRISTELIKE STAAT?!}

Calvyn se ideaal was dat daar ' $n$ teokratiese of Christelike staat moet bestaan. Die kerk wou nie die taak van die staat oorneem nie, maar het dit beklemtoon dat die staatsowerheid (as burgerlike regering) na die evangelieverkondiging van die kerk (geestelike ryk) moet luister en hulle aan die heerskappy van God moet onderwerp en sy koninkryk moet bevorder en beskerm. Hierdie ideaal kon Calvyn in Genève nie werklik bereik nie (vgl Pont 1981:267; De Groot 1955:201-204). 
Dit is egter belangrik om in gedagte te hou dat Calvyn - vanuit sy koninkryksperspektief en vanweë sy standpunt dat die owerheid 'n instelling van God self is erkenning gegee het aan 'n onchristelike staat (vgl Baur 1965:105-106; Bohatec 1961:626-628).

Die feit dat die ideaal van ' $\mathrm{n}$ Christelike staat in 'n wêreld met soveel diversiteit, strominge, ideologieë en staatsteorieë uiters moeilik haalbaar is, beteken nie dat die saak daarmee ongeldig is nie. Dit bly opmerklik dat verskillende konfessies wat in die verloop van die sestiende en sewentiende eeu ontstaan het ten opsigte van onder meer die taak van die staatsowerheid, Calvyn se standpunte verwoord. Hier kan verwys word na die Nederlandse Geloofsbelydenis (1561), die Skotse Konfessie (1560) en die Westminsterkonfessie (1647), om enkeles te noem. In elkeen word dit bely dat die owerheid die kerk moet beskerm en ondersteun, die belange van die koninkryk van God moet bevorder en moet meewerk om die ryk van die antichris te vernietig (vgl Fowler 1988:24-26).

Terloops moet gestel word dat 'n bepaalde sinsnede in artikel 36 van die Nederlandse Geloofsbelydenis - waarin melding gemaak word van die taak van die owerheid ten opsigte van afgodery, valse godsdiens en die ryk van die antichris - dikwels in die geskiedenis van die reformatoriese kerke verstaansprobleme geskep het en deur sommige kerke weggelaat is (vgl Polman sa:305-315).

Die sin onder bespreking in artikel 36 lui soos volg:

En dit is nie alleen hulle taak om aan die staatsbestuur aandag te gee en daaroor te waak nie maar ook om die heilige Woordbediening te beskerm, om sodoende (my kursivering) alle afgodery en valse godsdiens teen te gaan en yit te roei, die ryk van die antichris te vernietig en die koninkryk van Jesus Christus te bevorder, die Woord van die evangelie orals te laat verkondig, sodat God deur elkeen geëer en gedien word soos $\mathrm{Hy}$ in sy Woord beveel.

Hierdie vertaling gaan waarskynlik op grond van die Franse en Nederlandse tekste uit van die standpunt dat die taak van die owerheid volgens artikel 36 slegs tweërlei is, naamlik om te sorg vir die burgerlike regering en om die hand aan die kerkediens te hou. Wat verder volg, sou dan nie 'n uitbreiding van die taak van die owerheid wees nie, maar slegs ' $n$ beskrywing of 'n belydenis van die doel van die uitoefening van die tweërlei amp. Daarom is die woord 'sodoende' ingevoeg om daarmee aan te dui wat die doel of gevolg van die uitoefening van die take is (vgl GKSA 1973:192194; 1979:478). De Groot (1955:164-185) het aangetoon dat hierdie standpunt nie heeltemal oortuig nie omdat dit in stryd is met die duidelike uitsprake van Calvyn en veral ook van Guido de Brés, die opsteller van die belydenisskrif (vgl De Groot 1955:168-169). 
Dit is inderdaad die geval dat die huidige Afrikaanse vertaling probleme skep, want nadat die sogenaamde tweërlei taak van die owerheid geformuleer is, volg daar - behalwe die verwysing na die uitroeiing van die afgodery en die vernietiging van die ryk van die antichris - byvoorbeeld nog die sin 'om die koninkryk van Jesus Christus te bevorder'. Is die bevordering van die koninkryk van Jesus Christus slegs die gevolg van die beskerming van die kerk, of is dit ook 'n bepaalde taak en verantwoordelikheid van die owerheid?

Uit ons uiteensetting hierbo behoort dit duidelik te wees dat die bevordering van die koninkryk van Jesus Christus sonder twyfel die eintlike taak van die owerheid is. Alles trek uiteindelik daarin saam!

Dit is sekerlik waar dat wat ons volgens artikel 36 van die owerheid se taak teenoor die kerk bely inderdaad 'n belydenis is. Tog is dit meer as net ' $n$ belydenis. Dit is ook die roeping van die owerheid om op eiesoortige wyse in die uitoefening van die burgerlike regering en tegelyk anders as die geestelike ryk, in diens van God en sy koninkryk te staan. Dit sal ook met uitsprake van Calvyn en met die reformatoriese denke (De Groot 1955:153-185) ooreenstem.

Dit impliseer weer dat die kerk geroep is om teenoor die staatsowerheid te getuig wat die oorsprong, grondslag, doel en diens van die staat basies behels.

\section{GEVOLGTREKKINGS}

Hoewel Calvyn 'n besondere noue relasie tussen die koninkryk van God en die kerk handhaaf en dit soms met mekaar vereenselwig, is dit duidelik dat hy daarvan oortuig is dat die koninkryk nog nie in sy volkomenheid gekom het nie. Die koninkryk dra daarom in hierdie wêreld 'n voorlopige karakter, hoewel dit in die harte van ware gelowiges teenwoordig is en Jesus Christus as die enigste Hoof en koning sy onderdane in alles onder sy genadige en soms tugtigende regering lei en versorg. Die geestelike ryk van Calvyn kan dus nie met die koninkryk van God vereenselwig word soos dikwels in sy tyd gebeur het nie.

Die geestelike en burgerlike regerings as die twee ryke wat God uit genade vir die mensdom beskik het, staan albei onder die heerskappy van Christus en is geroep tot diens aan God en die wêreld.

'n Staatsowerheid sal die onderdane of volk oor wie hy regeer die beste dien wanneer hy in sy regering aan die koninkryk van God diensbaar is.

Die belange van die koninkryk van God gaan vooraf aan die belange van die onderdane, want as die koninkryk van God en sy geregtigheid gesoek word sal God al die ander dinge wat ons nodig het wel aan ons gee. 
Die geestelike en burgerlike ryke moet volgens Calvyn duidelik van mekaar onderskei word, want elkeen het sy eie aard, funksie en taak. Die gemeenskaplike lê daarin dat albei in diens van die koninkryk van God is en die onderskeid bring mee dat hulle ook tot diens aan mekaar geroep is sonder dat die een die ander oorheers.

Die burgerlike regering regeer oor 'n gemeenskap van mense wat nie noodwendig almal gelowig is nie; dit hoef ook nie slegs oor een bepaalde volk te regeer nie omdat die staat of gebied waaroor hy regeer uit 'n veelheid van volke kan bestaan (vgl Du Plessis 1932:55).

In Calvyn se denke is daar nie 'n duidelike aanduiding van 'n staatskerk of van 'n volkskerk (vgl Pont 1986:28-76) nie en ook nie van 'n kerkstaat nie. Die kerk (geestelike ryk) word eerder in sy direkte verband met die koninkryk van God gesien. Insgelyks is daar geen vermenging of integrasie van die geestelike regering met die burgerlike of politieke regering nie (vgl Snyman 1977:346-348; De Groot 1955:195-196).

Die koninkryk van God vind nie vergestalting in 'n volk, 'n staat of staatsowerheid as sodanig nie, maar in die kerk as 'n geestelike geloofsgemeenskap. In die kerk is gelowiges van een of meer volke natuurlik opgeneem en hulle word op grond van die genadeverbond deur geloof en doop deel van die Godsvolk wat oor die grense van volke, tale en nasies strek (vgl Du Plooy 1990:227-249; McNeil 1988:4355). ' $n$ Staatsowerheid regeer oor 'n bepaalde gebied en is daar geroep tot diens en tot beskerming en verdediging van die kerk en die koninkryk van God.

\section{SIOT}

In die ideologies-gepolariseerde en gepolitiseerde samelewing waarin ons ons bevind, word tereg gevra wat die rol en taak van die kerk en staat is. Die eise van die tyd dring ons terug tot by die wortels van die kerk en die staat.

Calvyn het ons geleer om prinsipieel te dink en om in ons vrae na die prinsipes van die kerk en die staat by God en sy koninkryk te begin. Met verwysings na verskillende uitsprake van Calvyn in sy kommentare haal Balke (1973:291-292) hom soos volg aan:

Geen mens, geen vors en geen onderdaan (mag) het zich aanmatigen om niet aan wetten (ordinatio Dei) gebonden te zijn...En waar Gods geboden gehoorzaamd worden, daar regent de gerechtigheid, dat is de goede en geregelde orde, uit de hemel. Hét geneesmiddel in de toestand van verwarring is de bijeenvergadering van de kerk. Een wereld in wanorde en verwarring heeft de kerk nodig. De verkondiging van 
het Evangelie is de beste remedie tegen het anarchisme, de chaos en de 'confusio'. Waar het Evangelie komt begint de 'recreatio' en wordt de orde van God hersteld.

\section{Literatuurverwysings}

Balke, W 1973. Calvijn en de doperse radicalen. Amsterdam: Bolland.

Baur, J 1965. Gott, Recht und Weltliches Regiment im Werke Calvins. Bonn: Bouvier. Berkhof, L 1969. The history of Christian doctrines. London: Banner of Truth Trust.

Bohatec, J 1961. Calvins Lehre von Staat und Kirche mit besonderer Berucksichtigung des Organismusgedankens. Aanlen: Scientia.

Calvyn, J 1845. Commentary on a harmony of the evangelists, Matthew, Mark and Luke, vol 2. Transl by W Pringle. Edinburgh: Edinburgh printing company.

--- 1864-1897. Ioannis Calvini opera supersunt omnia, band 29. Baum, G, Cunitz, E \& Reuss, $E$ (eds). Brunsvigae: Schwetschke et filium.

--- 1961. The gospel according to St John 11-21 and the first epistle of John. Torrance, W \& Torrance, T F (eds). Transl by T H L Parker. Edinburgh: Oliver \& Boyd.

-.- 1965. The epistles of Paul the apostle to the Galatians, Ephesians, Philippians and the Colossians. Torrance, W \& Torrance, T F (eds). Translated by T H L Parker. Edinburgh: Oliver \& Boyd.

--- 1980. Institusie van die Christelike godsdiens (1536). Vertaal deur H W Simpson. Potchefstroom: Calvyn Jubileum Boekefonds.

-- 1988. Institusie van die Christelike godsdiens, deel 3. Vertaal deur H W Simpson. Potchefstroom: Calvyn Jubileum Boekefonds.

--- sa. Institutie of de onderwijzing in de Christelijke religie. Amsterdam: Bottenburg.

De Groot, D J 1955. De reformatie en de staalkunde. Franeker: Wever.

Du Plessis, L J 1932. Die staatsteorie van Jean Calvin in vertand met die wetenskap en staatspraktyk van sy yd. Kampen: Kok.

Du Plessis, L M 1974. Calvyn oor die staat en die reg. Instituut vir die bevordering van Calvinisme (red). Potchefstroom: PU vir CHO.

--- 1986. Calvin on state and politics according to the Institutes, in Institute for Reformational Studies (ed), John Calvin's Institutes: His opus magnum, 174-183. Potchefstroom: PU for CHE.

Du Plooy, A le R 1982. Kerkverband: 'n Gereformeerd-kerkregtelike studie. ThDproefskrif, Potchefstroomse Universiteit vir Christelike Hoër Onderwys. 
Du Plooy, A le R 1990. 'n Kerkregtelike verkenning van die belewing van kerklike eenheid in en oor volks- en taalgrense. In die Skriflig 24, 227-249.

Fowler, S 1988. The State in the light of the Scriptures. Institute for Reformational Studies (ed). Potchefstroom: PU for CHE.

Gereformeerde Kerke in Suid-Afrika 1973. Nasionale Sinode: Handelinge van die 38ste sinodale vergadering. Potchefstroom: Potchefstroom Herald.

--- 1979. Nasionale Sinode: Handelinge van die 40ste sinode. Potchefstroom: Potchefstroom Herald.

Landwehr, J H 1924. Handboek der kerkgeschiedenis, deel 3. Kampen: Kok.

Lindijer, C H 1962. Kerk en koninkrijk. Amsterdam: Ten Have.

Lubbe, W J G 1964. Calvyn en die staat. NGTT 5, 200-208.

McNeil, J T 1988. Calvin as an Ecumenical Churchman. Church History 57, 43-55.

Milner, B C 1970. Calvin's doctrine of the church. Leiden: Brill.

Plöchl, W M 1960. Geschichte des Kirchenrechts, Band 1. 2. Auflage. München: Herold.

Polman, A D R sa. Woord en belijdenis: Eenvoudige verklaring van de Nederlandse geloofsbelijdenis, Deel 2. Franeker: Wever.

Pont, A D 1981. Die historiese agtengronde van ons Kerklike Reg, Deel 1. Pretoria: HAUM.

--- 1985. Thomas Erastus oor die struktuur van die gemeenskap. HTS 41, 428-440.

..- 1986. Verbond en volkskerk. HTS 42, 28-76.

Schoch, S 1902. Calvijn's beschouwing over kerk en staat. DD-proefskrif, RijksUniversiteit te Utrecht.

Snyman, W J 1977. Nuwe en ou dinge uit die skat van die koninkryk. (Red P C Snyman.) Potchefstroom: Pro Rege.

Steenkamp, J J 1986. Calvin on the 'state' in the Institutes, in Institute for Reformational Studies (ed), John Calvin's Institutes: His opus magnum, 353-374. Potchefstroom: PU for CHE. 